\title{
Discussion Paper \\ Meet People Where They Are: Building Formal Credit Using Informal Financial Traditions
}

Tom Akana

Federal Reserve Bank of Philadelphia

Consumer Finance Institute
DP 20-01

February 2020

https://doi.org/10.21799/frbp.dp.2020.01 


\title{
Meet People Where They Are: \\ Building Formal Credit Using Informal Financial Traditions
}

\author{
Tom Akana* \\ Federal Reserve Bank of Philadelphia
}

February 2020

\begin{abstract}
The Consumer Finance Institute hosted a workshop in February 2019 featuring José Quiñonez, chief executive officer, and Elena Fairley, programs director, of Mission Asset Fund (MAF) to discuss MAF's approach to helping its clients improve access to mainstream financial markets. MAF's signature program, Lending Circles, adapts a traditional community-based financial tool known as a rotating savings and credit association (ROSCA) to help establish or expand credit reports for participants who may not be able to do so through traditional means. Lending Circles have served more than 10,000 clients since 2007 and have expanded well beyond MAF's core constituency in the Mission District of San Francisco. Quiñonez and Fairley discussed MAF's approach to working with the communities it serves and shared the key successes and challenges that MAF has encountered. This paper provides an overview of the information shared in the workshop and additional research connecting Lending Circles to previous work on ROSCAs.
\end{abstract}

Keywords: rotating savings and credit association (ROSCA), financial inclusion, credit invisibles, underserved, unbanked, fintech, financial technology

JEL codes: D14, D71, D91

*Federal Reserve Bank of Philadelphia, Ten Independence Mall, Philadelphia, PA 19106-1574; email:

tom.akana@phil.frb.org.

Disclaimer: This Philadelphia Fed discussion paper represents preliminary research that is being circulated for discussion purposes. The views expressed in these papers are solely those of the authors and do not necessarily reflect the views of the Federal Reserve Bank of Philadelphia or the Federal Reserve System. Nothing in the text should be construed as an endorsement of any organization or its products or services. Any errors or omissions are the responsibility of the author. No statements here should be treated as legal advice. Philadelphia Fed discussion papers are free to download at https://www.philadelphiafed.org/consumer-finance-institute/publications. 


\section{Introduction}

On February 28, 2019, José Quiñonez and Elena Fairley of Mission Asset Fund (MAF) presented a workshop at the Federal Reserve Bank of Philadelphia (Philadelphia Fed). A number of Philadelphia-area community development organizations joined the Philadelphia Fed employees to learn about the development of MAF's Lending Circles, a lending approach designed to help unbanked and underbanked members of their local community gain access to the traditional financial market. Quiñonez and Fairley shared the history of the Lending Circles program and the successes and challenges that MAF has encountered in its first 10 years.

MAF was launched in 2007 with a \$1 million investment from the Levi Strauss Foundation to establish a nonprofit organization in San Francisco's Mission District. The goal was to identify ways to help Mission District residents improve their financial lives. Quiñonez, who has been with MAF since its founding, realized early that providing value to the community was not simply a matter of figuring out how to get residents to use banks or credit cards. His clients already knew that those products were available, but for a variety of reasons, they would not or could not access them. Instead, they were part of the financial "shadows" (i.e., individuals with lower incomes in a rising cost-of-living environment who have very limited access to traditional and mainstream affordable credit). ${ }^{1}$

Many of MAF's clients used payday lenders and similar resources with very high borrowing costs to cover unexpected or high-dollar expenses. ${ }^{2}$ Quiñonez referenced a white paper showing that unbanked and underbanked consumers can spend up to 10 percent of their income to access basic financial services. ${ }^{3}$ Existing financial products were not accessible or were not meeting the community's needs, so MAF had to think differently. In Quiñonez's words, they had to "meet people where they are, not where we want them to be." To that end, MAF took a very collaborative approach and spent time with Mission District residents, learning how they conducted their financial lives and managed their money. MAF found that, contrary to the typical perception of lower-income populations, the people in this community were financially savvy, creative, and innovative in their approach to managing their money. ${ }^{4}$

\footnotetext{
${ }^{1}$ Wherry, Seefeldt, Alvarez, and Quiñonez (2019) present a detailed history of MAF, exploring the social, political, and economic policies that have contributed to financial marginalization and racial wealth inequality in the United States.

${ }^{2}$ The Consumer Financial Protection Bureau (CFPB) published an analysis of payday installment loans covering 2 million account records from 2007 to 2014. The CFPB reported an average annual percentage rate (APR) of 268 percent and a median APR of 249 percent (Consumer Financial Protection Bureau, 2016).

${ }^{3}$ This value was derived in a 2014 white paper titled "Providing Non-Bank Financial Services for the Underserved" (Office of the Inspector General, U.S. Postal Service, 2014). The authors used data from multiple sources.

${ }^{4}$ This mirrors the conclusions of Mansell-Carstens (1996), who noted that the common assumptions about why people are underbanked (e.g., they don't understand the products, they have no income, and they are irresponsible
} 
Additionally, MAF found that 40 percent of its clients did not have traditional credit bureau records or credit scores, severely restricting their access to more conventional lower-cost credit. This affected their ability to access many types of affordable financial products, including personal and business loans, credit cards, and financial management services. ${ }^{5}$ MAF identified the lack of access to affordable financial products as one of the key factors preventing many of the Mission District's residents from achieving their financial goals. MAF decided to develop a program that would help members in its target community establish credit records with a national credit reporting agency. Along with this program, MAF was committed to providing financial literacy education. By combining these two tactics and adopting a human-centered approach to technology development, MAF aimed to meet its goal of developing high-quality services and tools to help consumers gain access to traditional credit and financial markets.

Rather than trying to modify an existing financial product, MAF adapted a lending tradition that was already well established with its clients. MAF created Lending Circles, a formalized version of a rotating savings and credit association (ROSCA), a common financial tool in the immigrant community it served.

\section{Rotating Savings and Credit Associations (ROSCA) - A Brief Overview}

Lending Circles are based on a common, informal form of community lending known by a variety of names around the world: tanda (Mexico), partner (Jamaica), hui (China), kye (Korea), chilemba (Central and East Africa), esusu (West Africa), dhikuri (Nepal), and numerous others (Chhetri, 1995; Hevener, 2006). Collectively, these are known as rotating savings and credit associations (ROSCAs) and have existed in one form or another for hundreds, if not thousands, of years. Geertz (1962) and Ardener (1964) are generally acknowledged to have provided the first broad-based descriptions of ROSCAs from around the world, basing much of their work on significant regional research done by anthropologists and sociologists through the early 20th century. The economic analysis of ROSCAs was limited until relatively recently when Besley, Coate, and Loury (1993) published "The Economics of Rotating Savings and Credit Associations" providing the first detailed evaluation of the economic effects of ROSCAs on the populations that use them.

with their money) often lead to poorly designed solutions by traditional commercial and government institutions. This ultimately leads to lower availability and a higher cost of "traditional" financial products for these populations.

${ }^{5}$ Brevoort, Grimm, and Kambara (2015) provide a detailed analysis of the financial impact to consumers of having a limited or nonexistent credit bureau record. 
Ardener defined a ROSCA as "an association formed upon a core of participants who agree to make regular contributions to a fund which is given, in whole or in part, to each contributor in rotation" (Ardener, 1964, p. 201). They appear typically among cultures that lack established financial markets or within subgroups that lack access to established financial markets (Geertz, 1962; Ardener 1964, Donoso, Altunbas, and Kara, 2011). While variations exist in the execution across different cultures and types of ROSCAs, certain characteristics appear consistently, as observed by Wu and Hutchins (2015): a defined life span or number of contributions, a leader/coordinator who forms the group and manages the incoming and outgoing funds, an established contribution amount, and the expectation of a one-time payout to each participant. For illustrative purposes, consider a very simple example of a ROSCA involving five individuals (Figure 1).

\section{Figure 1: Basic ROSCA Structure}

\begin{tabular}{|c|c|c|c|c|c|c|}
\hline \multirow[b]{2}{*}{ Participant } & \multicolumn{5}{|c|}{ Contributions } & \multirow[b]{2}{*}{ Total } \\
\hline & Month 1 & Month 2 & Month 3 & Month 4 & Month 5 & \\
\hline Alice & 400 & 400 & 400 & 400 & 400 & 2000 \\
\hline Bernard & 400 & 400 & 400 & 400 & 400 & 2000 \\
\hline Clara & 400 & 400 & 400 & 400 & 400 & 2000 \\
\hline Desmond & 400 & 400 & 400 & 400 & 400 & 2000 \\
\hline Elsa & 400 & 400 & 400 & 400 & 400 & 2000 \\
\hline Total & 2000 & 2000 & 2000 & 2000 & 2000 & 10000 \\
\hline Pot Recipient & Alice & Clara & Desmond & Bernard & Elsa & \\
\hline
\end{tabular}

For example, Alice identifies an upcoming need for a large expenditure of $\$ 2,000$, for which she does not currently have the available funds. To make that expenditure sooner, she establishes a ROSCA and identifies four other members of her community with similar financial needs. They agree to each contribute $\$ 400$ per month to the ROSCA, and in exchange, each member will receive $\$ 2,000$ in one of the months. As the leader, Alice chooses to receive the first payout, and the remaining members receive their money based on a random drawing of a name each month, with Elsa receiving the money last. ${ }^{6}$ This

\footnotetext{
${ }^{6}$ There are a variety of specific implementations of the payout process in traditional ROSCAs. Besley, Coate, and Loury (1993) describe and analyze two of the most common types as random and bidding ROSCAs. In a random ROSCA, all participants agree to contribute a specific amount each month, and all will receive an equal payout, with the order of payout determined through a random drawing each month from the pool of participants who are still awaiting their payout. In a bidding ROSCA, participants bid each month for the right to receive the payout sooner;
} 
example contains each of the common characteristics: defined lifetime (five months), leader (Alice), contribution amount (\$400), and established payout schedule (random draw).

Both the anthropological and economic literature acknowledge that the primary force ensuring the success of ROSCAs is the social nature of the agreements. As informal agreements that may or may not have documentation, ROSCAs have few if any legal protections available to ensure that members continue to meet their obligations. Since ROSCAs traditionally exist outside the established financial systems, the fear of hurting a credit rating or having wages garnished does not exist. In the example in Figure 1, there is no explicit creditor remedy that would preclude the early recipients of the pot (Alice and Clara) from ceasing their contributions in the later months. Researchers cite the high risk of social consequences as the primary factor ensuring compliance to the ROSCA agreements.

Wu and Hutchins point out that, while ROSCAs are "not per se illegal," they are not legally binding and operate based on "naked social trust" (Wu and Hutchins, 2015, p. 25). Ardener notes that members who default put their future economic access at risk, as they "may not be accepted as a member of any other" ROSCA (Ardener, 1964, p. 216). In an overview of Mexican tandas, Mansell-Carstens observed that members who fail in their obligations to the ROSCA "can lose their reputation - and their friends" (Mansell-Carstens, 1996, p. 79). In Kurtz's examination of a cundina in southern California, he commented that defaults were commonly addressed "through such tactics as gossip, ostracism, and, on occasion, violence," rather than attempting to involve official channels (Kurtz, 1973, p. 52). Last, Besley et al. (1993) pointed out that the key to understanding ROSCAs is to remember that "unlike markets, they are not anonymous institutions" (Besley et al., 1993, p. 805). The fact that people tend to enter ROSCAs with family, friends, or community members presents participants with a much higher level of perceived obligation that leads to much lower reported default rates.

Investigations ensued asking why ROSCAs appear across such a variety of cultures. Presumably, they provide a concrete benefit to participants not obtainable through more traditional channels. The general consensus among ethnographers and anthropologists focuses on participants' outsider status ROSCAs usually (although not always) manifest in societies' marginal populations, for instance in impoverished or immigrant communities. This view posits that ROSCAs provide a means of saving or borrowing to groups without access to such products through traditional financial markets. Besley, Coate, and Loury (1994) examined the economic outcomes of ROSCAs and reported that their findings generally supported this theory, particularly in cases in which the ROSCAs were being used to access a specific,

\footnotetext{
they essentially bid a discount amount, which is then deducted from the monthly contributions of the other participants. Hevener (2006) and Wu and Hutchins (2015) both provide excellent descriptions of the mechanics of bidding ROSCAs.
} 
high-cost good. A variety of research since then has examined ROSCAs in the context of savings and borrowing (Besley et al., 1994; Kovsted and Lyk-Jensen, 1999), management of financial self-control (Ambec and Treich, 2007), and consumption pressures (Donoso et al., 2011). In the majority of examples in the literature, people use a ROSCA because it provides them with access to a financial tool that is not available to them otherwise.

\section{Mission Asset Fund and the Launch of Lending Circles ${ }^{7}$}

An MAF Lending Circle consists of a group of between six and 12 clients who agree to participate in the program based on similar financial needs (e.g., they all anticipate needing $\$ 1,000$ to finance a purchase, pay another debt, or support a small business expense). ${ }^{8}$ MAF identifies the clients through an application process, during which prospective participants must provide valid identification, contact information, and proof of income. Proof of income can include a variety of materials, including pay stubs, bank statements, benefits letters, or household income. An applicant's debt-to-income must be below 50 percent to qualify.

Financial education is another key component of MAF's program. Clients have access to a smartphone application and online resources covering a variety of financial concepts, such as credit, savings, and self-employment. The self-directed content consists of 30 modules and is designed to help clients reflect on their financial goals with the long-term goal of improving their overall financial health. The variety of content allows a client to customize materials to his or her personal targets, experience, and education level. Prior to their participation in a Lending Circle, clients are required to complete at least five of these modules, ensuring that they enter the program with a reasonable knowledge base of what they expect to accomplish (60 percent of loan clients complete more than the minimum). Fairley noted that the financial training modules are available to all clients of MAF, regardless of their participation in a Lending Circle.

Once a client has completed the application and education requirements, MAF coordinates a faceto-face meeting with the eligible participants to finalize the details of the Lending Circle. Details discussed in this meeting include the size of the contribution/payout and the order in which participants will receive the payout. The order could be based on a random draw or negotiated among the participants

\footnotetext{
${ }^{7}$ Note: Unless otherwise indicated, information relating to Mission Asset Fund or Lending Circles was obtained from the presentation made by Quiñonez and Fairley at the Federal Reserve Bank of Philadelphia on February 28, 2019, or from the Mission Asset Fund website.

${ }^{8}$ As of 2018, Lending Circles averaged nine participants with monthly contributions of $\$ 109$ (a total loan size of \$981). There are generally around 125 active Lending Circles at any given time.
} 
based on need. Because the participants in the MAF program are not necessarily socially connected in the same way as participants in a typical ROSCA are, the meetings serve as a proxy for the social aspect of the local tandas to which the clients are more accustomed. MAF considers these meetings crucial to the success of the Lending Circles - clients who have met each other in person seem to have a stronger connection to the program and are less likely to default, even if the social pressures are not as powerful as they may be in community-led ROSCAs.

Once the group is finalized and agrees to the terms, the process of setting up the Lending Circle electronically begins. MAF developed proprietary software to manage contributions and payouts for the Lending Circles, all of which are handled automatically, which lowers the risk of defaults or payment delays. Because of the automated nature of the process, clients are required to have a demand deposit account (DDA). For clients who do not have a DDA at a U.S. bank, MAF helps them get appropriate accounts established with local credit unions. Once participants are set up, the Lending Circle begins operating and continues until all members have received a payout. MAF reports users' participation and payment information to the major credit reporting agencies as a personal loan, allowing the clients to start a credit report or to build on an existing report with a well-managed tradeline. ${ }^{9}$

In 2013, the César E. Chávez Institute (CCI) at San Francisco State University completed an independent analysis of the effect MAF's Lending Circles had on participants' credit scores and overall debt levels (Reyes, Lopez, Phillips, and Schroeder, 2013a, 2013b; Reyes and Lopez, 2016). The authors observed generally positive movements in credit scores for clients who successfully completed a Lending Circle. The population of participants without a credit score decreased from 28 percent at the beginning of the program to 3 percent at the end, demonstrating success in one of MAF's primary goals - helping clients establish a credit bureau record. ${ }^{10}$ For clients who already had a score when entering a Lending Circle, CCI observed that their credit scores generally increased, with the strongest increases occurring for customers with lower scores. The 24 percent of clients with scores in the lowest range at the beginning of their participation improved by at least one range; half of those who remained still improved their scores by 20 points or more (Reyes et al., 2013a). Comparing movement between score ranges (Figure 2)

\footnotetext{
${ }^{9}$ Lending Circles are reported as personal installment loans to the credit reporting agencies. The loan amount is the total disbursement, the term is the number of months the Lending Circle is active, and the payment due is the monthly contribution. For example, based on the statistics referenced in the previous footnote, an average Lending Circle participant in 2018 would have a \$981 loan with a \$109 monthly payment amount and a term of nine months on his or her credit file.

${ }^{10}$ Reyes et al. (2013a) examined the pre- and post-completion credit scores of Lending Circle participants who started and completed their first Lending Circle prior to January 18, 2013.
} 
reveals generally that clients improved their credit scores, with 36 percent of the population moving to a higher score range in the CCI data.

Figure 2: Lending Circle Participant Score Improvements

\begin{tabular}{|c|c|c|c|c|c|c|c|}
\hline & \multicolumn{6}{|c|}{ Post-Participation Credit Score } \\
\hline & & No Score & $<580$ & $581-619$ & $620-719$ & $>=720$ & $\begin{array}{c}\text { Total } \\
\text { Distribution }\end{array}$ \\
\hline \multirow{6}{*}{$\begin{array}{c}\text { Pre-Participation } \\
\text { Credit Score }\end{array}$} & \multirow{2}{*}{$\begin{array}{c}\text { No Score } \\
<580\end{array}$} & $3 \%$ & $2 \%$ & $3 \%$ & $17 \%$ & $3 \%$ & $28 \%$ \\
\hline & & $0 \%$ & $12 \%$ & $3 \%$ & $1 \%$ & $0 \%$ & $17 \%$ \\
\hline & $581-619$ & $0 \%$ & $2 \%$ & $2 \%$ & $4 \%$ & $0 \%$ & $9 \%$ \\
\hline & $620-719$ & $0 \%$ & $2 \%$ & $2 \%$ & $25 \%$ & $3 \%$ & $32 \%$ \\
\hline & $>=720$ & $0 \%$ & $0 \%$ & $0 \%$ & $3 \%$ & $12 \%$ & $15 \%$ \\
\hline & Total & $3 \%$ & $19 \%$ & $10 \%$ & $51 \%$ & $18 \%$ & $100 \%$ \\
\hline
\end{tabular}

\begin{tabular}{|c|c|}
\hline Decrease Score & $9 \%$ \\
\hline Neutral Score & $54 \%$ \\
\hline Increase Score & $36 \%$ \\
\hline
\end{tabular}

Source: Author's recreation of data from Reyes et al. (2013a)

To evaluate whether the improvements could be attributed to Lending Circle participation, CCI evaluated results for a propensity-matched control population of clients who did not participate in a Lending Circle (the treatment group consisted of a subset of clients who participated in a Lending Circle during the observation period). For the two metrics reported previously, the treatment group of Lending Circle participants showed larger improvements than the control population. The percentage of control group clients without a credit score decreased from 31 percent to 27 percent, versus the treatment group that decreased from 29 percent to 9 percent. For clients with a score at the beginning of the observation period, the control population's average credit score decreased by 16 points, whereas the treatment population experienced an increase of 19 points.

In addition to the observed improvements in credit score, the CCI authors note that participants with credit files at the beginning of the observation period were able to significantly reduce (in both the economic and statistical sense) their outstanding debt compared with the control group. Average balances decreased by $\$ 2,483$ for program participants, whereas members of the control group increased their debt 
by $\$ 2,772$. The CCI authors conclude that Lending Circles are generally successful in improving the financial access and well-being of the participants.

MAF's electronic management applications afforded Lending Circles early success and scalability, which allowed Lending Circles to expand beyond the Mission District beginning in 2011. MAF now works with 65-plus community organizations across 18 states and the District of Columbia to bring Lending Circles to a wide variety of communities. Fairley noted that, as of January 2019, MAF has facilitated \$10 million in loans through Lending Circles to more than 10,000 clients, and nearly all participants have successfully completed their obligations (CCI notes that the percentage of MAFmanaged Lending Circles reported as 90 days or more past due is half the rate of the $\mathrm{S} \& \mathrm{P} /$ Experian Consumer Credit Default Composite Index (Reyes et al., 2013b, p. 9). ${ }^{11}$

\section{MAF Technology and the Launch of MAF Lab}

A belief in the importance of strong technology has been embedded in MAF's approach to its mission since the beginning. Quiñonez believes that the tools required to support MAF's clients need to be as human centered and collaborative as the programs themselves. That approach has led to a number of unusual decisions relating to technology for the nonprofit space, decisions which could potentially benefit other nonprofits.

Quiñonez was keenly aware of the high cost of originating and servicing the type of small dollar loans that MAF was designing, particularly for immigrant and underbanked populations. When a bank has similar operational costs to maintain a $\$ 500$ loan as a $\$ 5,000$ loan, it will naturally favor the larger loan amount that generates higher income and lower credit risk. Banks often end up deprioritizing or eliminating small dollar lending because of this phenomenon; Castellanos, Hernández, Mahajan, and Seira (2018) provide a strong analysis of the dynamics that lead to banks eliminating these types of loans, which are often products intended to serve underbanked populations. Quiñonez knew that designing a product that required high maintenance costs (e.g., resources to handle cash or checks, or mail processing services to send statements) would likely lead to failure. He believed that using technology effectively would eliminate these cost barriers.

\footnotetext{
${ }^{11}$ Per MAF, clients are reported as delinquent when they are 30 days past due and will remain in a delinquent status until write-off. Since 2016, MAF noted that 16 percent of clients have missed one payment, 4 percent are reported as 30 -plus days past due, and 2 percent are reported as 90 -plus days past due; 0.7 percent ultimately reach default status.
} 
From the beginning, MAF was committed to devoting high levels of funding and attention to technical development, believing that shortcuts on technical solutions would lead to underdeveloped tools and lower client engagement. MAF's philosophy of meeting people where they are extends to the tools clients use, so clients are directly involved in the development process, from conception to prototyping to post-release feedback. As Quiñonez repeats in many of his talks, the clients "are the experts in their own lives." From a technical perspective, that means building tools tailored for the ways that MAF's client base prefers to access and assimilate information. This "community-centered approach to design thinking" is rooted in the same core philosophy that led to building the Lending Circles product based on the preexisting social and financial structures of the community.

To achieve the high level of cost consciousness required to meet its goals, MAF's leadership decided that all development would take place in-house, using external technical resources only when needed. This gives MAF a high level of flexibility to manage requirements, cost, and development cycles for its projects. The in-house development team used widely available best-in-class rated platforms to build the systems (e.g., Salesforce, Twilio, and DocuSign, among others). These platforms provide longterm stability, embedded privacy and security, and an established level of quality. The strong technical infrastructure allowed MAF's unique loan and grant products to be built creatively, without having to focus as much time or money on adapting or building the underlying technology.

MAF's belief in the importance of human-centered program design and the criticality of the technology underpinning its programs led to the creation of MAF Lab within the organization in 2017. MAF Lab formalized the development and technical approaches MAF had employed since its founding and ensures continued organizational focus on innovation. Ramya Gopal, the head of the MAF Lab team since its creation, brought experience as a researcher/analyst working with philanthropic organizations to help them better utilize data and technology to improve their programs' effectiveness. MAF's technical and development goals, enumerated by Gopal when she joined the company (Gopal, 2018), start with identifying the best use of development resources first:

- Uncover pressing unmet needs of the communities we serve.

- Understand the practices, relationships, and resources of these communities.

- $\quad$ Expand the types of financial needs supported through MAF's programs and products.

- Improve the relevance and usability of programs and products to address users' needs. ${ }^{12}$

- $\quad$ Share our [MAF's] research and experiences with other organizations.

\footnotetext{
${ }^{12}$ Gopal noted that one relatively small design decision has received some of the most positive feedback: The avatars representing people in the app were tweaked to better exemplify the demographics of MAF's users. Clients have reported back to MAF that this app is one of the first financial tools they have used that they felt genuinely represented them.
} 
- Provide research, design thinking, and technology services to leading nonprofits, foundations, and corporations.

MAFs ongoing projects focus on improving core functionality (such as redesigning and improving the mobile application process), as well as addressing the future needs of its clients and partners. This includes embedding concepts derived from MAF's "Hierarchy of Financial Needs" and the Consumer Financial Protection Bureau's Principles of Financial Education into the online training modules (CFPB, 2017). ${ }^{13}$ The highest profile release to date has been the MyMAF app for mobile phones. While MAF's loan application forms and web pages have always been mobile friendly, the native mobile app improves MAF's ability to engage with its clients through their phones. The new app provides clients with access to tools that help them narrow their current priorities, present the most relevant training or programs for where clients are on the hierarchy, and manage their progression through the training.

Understanding client needs going into a development project improves the likelihood that the end product will achieve the desired outcomes. One of MAF's more important ongoing needs, according to Gopal, is analyzing the impact the technology has had on clients. MAF Lab develops measurement tools and techniques that allow the organization to evaluate the effects of the changes, allowing adjustments to be made after launch. MAF's primary purpose is to help its clients achieve financial goals; if the tools provided to the clients are not effectively contributing to that purpose, then the team will know that quickly and can change course as needed.

\section{Moving Beyond Lending Circles}

In addition to Lending Circles, MAF developed and launched two additional programs targeted to help immigrants manage expenses related to immigration and citizenship. MAF created the first program in 2017 to help people affected by changing policies and government deadlines related to the Deferred Action for Childhood Arrivals (DACA) program. ${ }^{14}$ MAF provided $\$ 3.9$ million in grants to assist 7,932 DACA recipients with fees associated with renewing their status before the program was frozen in early 2019. In the second program, MAF provides interest-free loans to cover select U.S. Citizenship and

\footnotetext{
${ }^{13}$ MAF's "Hierarchy of Financial Needs" is described by Quiñonez in a blog post as reimagining Abraham Maslow's Hierarchy of Needs: five levels of human needs that are required to become a fully self-actualized individual (Quiñonez, 2015). Quiñonez adapted the traditional hierarchy to address economic self-actualization, identifying income, insurance, credit, savings, and investments as the five financial needs that ultimately need to be fulfilled for individuals to achieve economic success.

${ }^{14}$ Information on the DACA program can be found on the U.S. Citizenship and Immigration Services (USCIS) archived DACA information page.
} 
Immigration Services (USCIS) filing fees, such as U.S. Citizenship applications, Green Card applications, DACA renewals, Temporary Protected Status applications, and Petition for Relative requests.

Performance on all loan products are reported by MAF to credit reporting agencies and, therefore, contribute to building credit bureau records for their clients. As with Lending Circles, MAF requires applicants to complete the online financial education to qualify for these loans.

\section{Lessons Learned and Looking Forward}

Fairley discussed some of the key findings that MAF has made in the 10 years that it

\section{ALICIA'S STORY}

Alicia became known in the community for her tamales, which she began selling door-to-door in 2001. While her food was popular and her income relatively steady, she was limited by her access to equipment and facilities to selling 100 tamales a week.

Alicia participated in her first Lending Circle in 2010, taking advantage of the education courses to create business plans and budgets and using the payouts to improve her credit and save for future supplies and equipment including a food cart that helped her increase her sales.

Alicia continued to grow her business and improve her credit. That led to access to more traditional small business lending where she could get larger loans than Lending Circles can give.

With access to the traditional loan market, Alicia was able to obtain funding to open a full factory in 2016. She now has 17 employees, makes 40,000 tamales a month, and is a wholesaler to Whole Foods and Berkeley Bowl in the San Francisco area.

has been providing services to its clients. According to MAF, larger financial providers and regulatory bodies often overlook the fact that the unbanked, underbanked, and immigrant populations are more diverse and financially savvy than is generally assumed. MAF has identified three typical client profiles:

- Establishing: Covering the traditional image of the unbanked population, this encompasses consumers who have minimal or no presence in the financial system and are seeking to gain access to banking and credit in the U.S.

- Repairing: Clients who have previous negative credit experiences and need education and support to regain access to the traditional credit market.

- Building: Clients who have established a credit presence and are looking to increase their access to lower-cost traditional credit products. Fairley shared the story of Alicia, a client who benefited significantly from her participation in Lending Circles to build credit and expand her business (see sidebar above). 
In working directly with its clients and its expanding partnerships, MAF has collected significant data on a population that is often invisible to traditional analysis. MAF is currently embarking on detailed analysis of these data and shared a few highlights:

- Despite fewer resources and limited access to traditional banking services, 57 percent of clients are still able to save money outside mainstream systems. ${ }^{15}$

- The community is a key component of the informal financial market, with 42 percent of clients exhibiting some level of financial interdependence with nonhousehold members. This can take the form of traditional ROSCA relationships, direct borrowing from friends, or shared living arrangements.

- A portion of Lending Circle participants are successfully transitioning into asset ownership through traditional lending while still participating in a Lending Circle; 8 percent of clients added a mortgage or auto loan while in their first Lending Circle.

- Clients make ends meet by using a variety of income strategies, with many citing formal employment as their primary source of income, even in cases in which they indicate that they receive income through multiple sources (43 percent of clients report having multiple income sources); 85 percent of the clients who report multiple incomes say that formal employment is part of their strategy (Figure 3). ${ }^{16}$

\footnotetext{
${ }^{15}$ Kurtz (1973), Besley et al. (1993), and Mansell-Carstens (1996) all discuss ROSCAs as a form of savings, particularly for participants who receive their payout in later cycles. While MAF's findings do not necessarily consider ROSCA participation as savings in this context, they are a common example of an informal savings tool.

${ }^{16}$ MAF defines formal employment as income derived from traditional employment and/or salaried work. Informal employment includes income from owning a small business, self-employment, odd jobs, and gig economy work.
} 
Figure 3: MAF Client-Reported Income Strategies

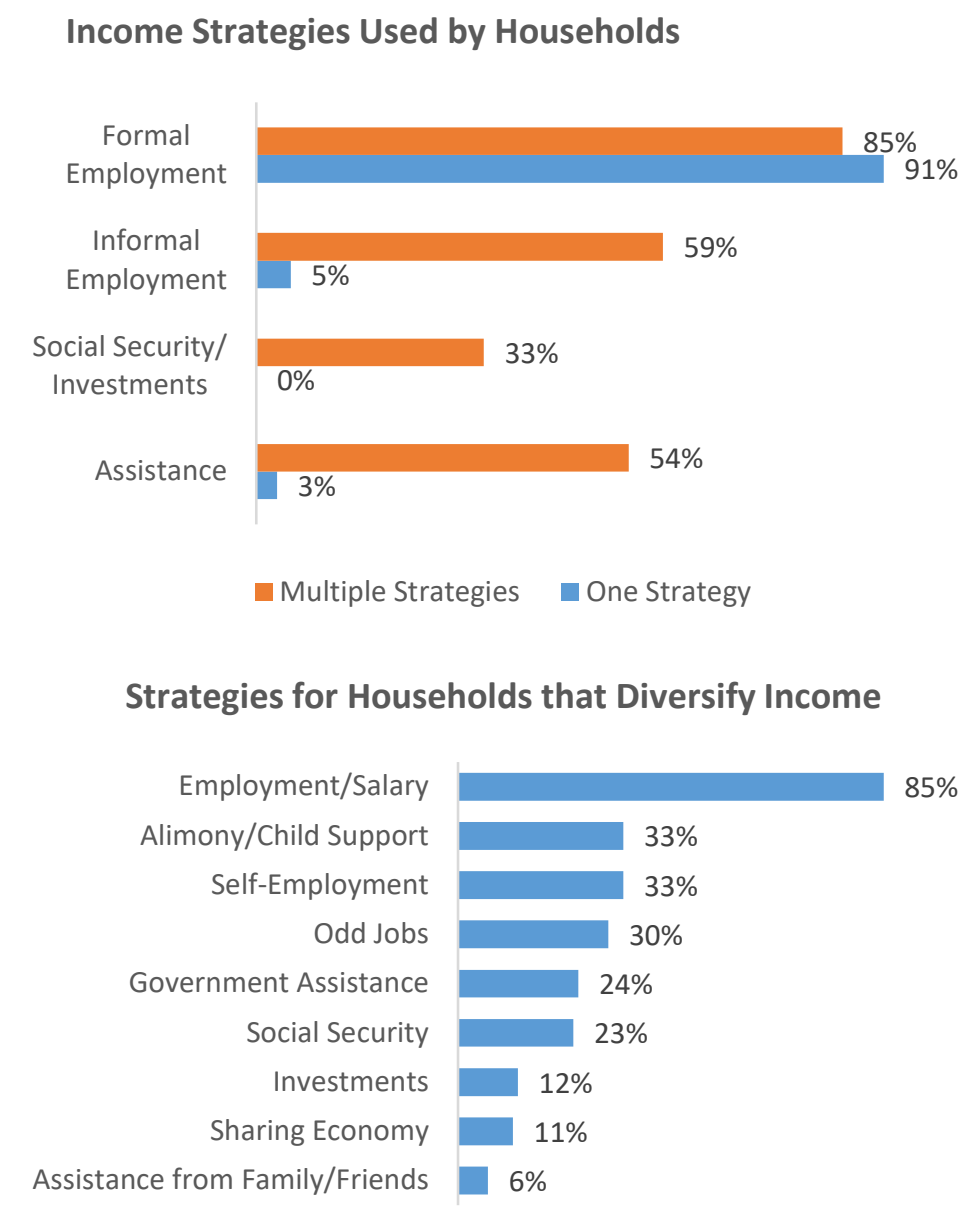

Source: MAF client survey results, supplied in presentation materials (February 28, 2019).

\section{The Future of Lending Circles and Serving the Unbanked}

Quiñonez spoke about the ongoing work to "change the discussion" about serving populations like the ones MAF has supported for the last 10 years. MAF identified a specific outcome (improving access to financial markets through establishing and improving clients' credit scores) and devised a unique toolset (an adaptation of the informal financial market backed by a focused digital platform) to achieve it. Based on the available information, it appears that MAF's work has shown promise, and its ability to license and expand the process beyond its core constituency is an argument in favor of its model. There are specific 
characteristics of MAF and the current environment that enabled that success as well as challenges that would have to be addressed legislatively to support its continued expansion.

Traditional financial institutions have tried to establish products or programs to accomplish what MAF has accomplished, but those attempts have generally met with little success. For example, Castellanos, Hernández, Mahajan, and Seira (2018) examined a financial inclusion program executed by a large financial institution in Mexico and observed that thin margins, inconsistent revenue, and higher default rates made the program challenging to maintain. The institution eventually discontinued it, and the authors concluded that these challenges would severely limit the scope and success of financial inclusion efforts through the formal sector.

MAF's status as a nonprofit supported by a network of donors large and small has enabled it to act more flexibly than a traditional financial institution. Without pressure to generate returns on the loans it makes, MAF is able to offer interest-free lending and low- or no-cost services to its clients. Quiñonez commented that MAF is very careful in how it positions itself to larger financial institutions, some of which are major funders, and to regulatory and legislative agencies. MAF argues that it is not trying to compete with banks in providing services or gaining customers; it is trying to fill a gap that banks cannot currently fill for a variety of reasons. To that end, MAF is trying to get its clients to the point where they can become good customers of institutions in the traditional banking sector; they are not expecting to fulfill all of their clients' financial needs. One example of this intention is a $\$ 2,500$ cap on loans provided by MAF. ${ }^{17}$ Clients seeking larger loans (such as auto, small business, or home loans) will move to traditional providers after successfully completing MAF's programs.

As noted previously, MAF sought to meet its clients where they are by adapting familiar, informal financial experiences. The key to MAF's program was creating a way to document and report clients' experience with the informal market to traditional credit bureaus, thereby supporting access to the formal banking sector. While this is certainly a net positive for clients who finish their Lending Circles without issue, it holds risk for clients who default, since they will now have negative information on their credit reports.

When discussing the high success rate of Lending Circles' participants, Quiñonez and Fairley acknowledged that clients do miss payments more frequently than the final numbers imply. Here, MAF and its partner organizations' direct involvement with clients becomes a significant asset; they can work

\footnotetext{
${ }^{17}$ Although individual loans are capped at $\$ 2,500$, there is no lifetime cap on loans to individual clients through MAF, and clients often participate in multiple Lending Circles over time.
} 
directly with struggling participants to ensure completion of their contributions. Reyes et al. (2013b) describe the approach to missed payments:

The contribution amount is electronically withdrawn on the 17th of every month from every lending-circle loan. If there are insufficient funds or the account is closed, MAF contacts clients to address the issue. For clients in partner agencies, the follow-up process varies across organizations and provides an opportunity to address particular issues confronting participants. After a month of nonpayment at MAF, clients are asked to speak to a financial coach to ensure that they get the support they need to address their financial hardships, make a plan, refinance the loans, or withdraw. (p. 9)

This hands-on process ultimately allows MAF to get nearly every client successfully through the Lending Circles using techniques that are highly effective, but of limited utility to larger traditional banks. Focusing on the mission of serving their clients in a very targeted manner rather than designing products that need to meet minimum financial hurdles allows this to happen. This is generally illustrative of the challenges as well as the advantages MAF faces when operating as a nonbank with products that would traditionally be managed under a particular regulatory and supervisory regime.

Quiñonez is aware of these challenges and believes that the overall benefit provided by programs like Lending Circles justifies the effort required to ensure that they continue to develop. To that end, he cited MAF's work with the California legislature to pass two key pieces of legislation. In 2014, SB 896 was passed, granting a licensing exemption to nonprofit organizations to allow them to offer zero-interest loans up to $\$ 2,500 .{ }^{18}$ This allows credit-building programs such as Lending Circles to develop and operate in a different manner than the traditional for-profit banks. SB 455 was passed in October 2019 to create a $\$ 4$ million fund that would direct money to nonprofits that develop effective financial education for at-risk populations in the state. ${ }^{19}$ The fund is supported through enforcement action penalties levied against payday lenders. Both of these laws allow a degree of operational freedom to nonprofits like MAF, which are not typically available to more traditionally regulated financial institutions.

\footnotetext{
18 “CA SB896 | 2013-2014 | Regular Session.” August 15, 2014, LegiScan, accessed March 19, 2019, https://legiscan.com/CA/bill/SB896/2013.

19 “CA SB455 | 2019-2020 | Regular Session.” March 8, 2019, LegiScan, accessed January 10, 2020, https://legiscan.com/CA/bill/SB455/2019.
} 
As MAF and other nonprofits across the country continue to engage with local communities by facilitating ROSCA-type lending opportunities, an open dialogue with state policymakers will be important to sustaining these models. ${ }^{20}$ Moreover, sustainability will require nonprofits to continue to police themselves to ensure that they are operating ethically because, ultimately, nonprofits must rely on the trust they have established with financial donors and with participants in the communities that they serve.

While MAF's approach to internally managed, human-centered design makes the organization unique in the nonprofit environment, Gopal believes that the principles under which it operates can and should be used across fintech and other nonprofit organizations. She believes that often tech companies that are developing financial services tools approach product design from the perspective of "fixing" the people they are trying to serve (echoing Mansell-Carstens's (1996) report of preconceived notions about unbanked and underbanked people). That leads to products that dictate habits to be changed and behaviors to be developed. The prescriptive features and rules built into those products increase the explicit and implicit costs for both the company and the customer, limiting the benefits. MAF approaches its development processes in a manner designed to avoid that trap.

MAF actively shares its work with its nonprofit partners at events such as Lending Circles Summits and other national conferences, helping to seed the principles of human-centered design and development within the larger nonprofit environment. MAF Lab also uses a 17-person volunteer Technology Advisory Council to engage technology experts as resources for guidance to ensure their approaches continue to result in the highest quality products. MAF's design principles allow it to develop tools that draw on the strengths of the population being served, just as Lending Circles draw on clients' existing financial experiences rather than attempting to install new ones.

MAF's Lending Circles program and technology provide a unique example of a product designed to address the needs of its customer base creatively by adapting to the habits and traditions of the community. Its success and growth through its first 10 years is a testament both to its value to the communities as well as its underlying design and execution. Quiñonez noted that MAF is currently working on a deeper analysis of the data it has collected through its first decade and expects to share more information gleaned from these analyses in the future. Because MAF continues to make its programs available to a broader population around the country, open sharing of the research findings will be crucial

\footnotetext{
${ }^{20}$ Nonprofits are generally chartered and incorporated at the state level, with specific governance rules varying from state to state. This complicates the task of scaling a program like Lending Circles.
} 
to ensure the transparency of its model as well as its successes and challenges, informing discussions with policymakers, market participants, and potential funders in the communities that MAF serves. 


\section{References}

Ambec, Stefan, and Nicolas Treich. 2007. "Roscas as Financial Agreements to Cope with Self-Control Problems," Journal of Development Economics, 82:1, pp. 120-137, https://doi.org/10.1016/j.jdeveco.2005.09.005.

Ardener, Shirley. 1964. "The Comparative Study of Rotating Credit Associations," The Journal of the Royal Anthropological Institute of Great Britain and Ireland, 94:2, pp. 201-229, https://doi.org/10.2307/2844382.

Besley, Timothy, Stephen Coate, and Glenn Loury. 1993. "The Economics of Rotating Savings and Credit Associations," American Economic Review, 83:4, pp. 792-810.

Besley, Timothy, Stephen Coate, and Glenn Loury. 1994. "Rotating Savings and Credit Associations, Credit Markets and Efficiency,” Review of Economic Studies, 61:4, pp. 701-719, https://doi.org/10.2307/2297915.

Brevoort, Kenneth P., Philipp Grimm, and Michelle Kambara. 2015. "Credit Invisibles,” Bureau of Consumer Financial Protection Data Point Series 15-1.

Castellanos, Sara G., Diego Jiménez Hernández, Aprajit Mahajan, and Enrique Seira. 2018. "Financial Inclusion and Contract Terms: Experimental Evidence from Mexico," Working Paper 24849, National Bureau of Economic Research, https://doi.org/10.3386/w24849.

Chhetri, Ram B. 1995. "Rotating Credit Associations in Nepal: Dhikuri as Capital, Credit, Saving, and Investment," Human Organization, 54:4, pp. 449-454, https://doi.org/10.17730/humo.54.4.f17uj648g43k3n75.

Consumer Financial Protection Bureau. 2016. "Supplemental Findings on Payday, Payday Installment, and Vehicle Title Loans, and Deposit Advance Products."

Consumer Financial Protection Bureau. 2017. "Effective Financial Education: Five Principles and How to Use Them,.” https://www.consumerfinance.gov/about-us/blog/effective-financial-education-fiveprinciples-and-how-use-them/ (accessed November 6, 2019).

Donoso, Sebastian Baixeras, Yener Altunbas, and Alper Kara. 2011. "The Rationale Behind Informal Finance: Evidence From Roscas in Bolivia," Journal of Developing Areas, 45:1, pp. 191-208, https://doi.org/10.1353/jda.2011.0000.

Geertz, Clifford. 1962. "The Rotating Credit Association: A 'Middle Rung' in Development,” Economic Development and Cultural Change, 10:3, pp. 241-263, https://doi.org/10.1086/449960.

Gopal, Ramya. 2018. "MAF Lab: R\&D for Social Good,” Mission Asset Fund, https://missionassetfund.org/introducing-maf-lab-using-rd-social-good/ (accessed January 10, 2020).

Hevener, Christy Chung. 2006. "Alternative Financial Vehicles: Rotating Savings and Credit Associations (ROSCAs)," 06-01, Federal Reserve Bank of Philadelphia. 
Kovsted, Jens, and Peter Lyk-Jensen. 1999. "Rotating Savings and Credit Associations: The Choice Between Random and Bidding Allocation of Funds," Journal of Development Economics, 60:1, pp. 143-172, https://doi.org/10.1016/S0304-3878(99)00039-5.

Kurtz, Donald V. 1973. "The Rotating Credit Association: An Adaptation to Poverty," Human Organization, 32:1, pp. 49-58, https://doi.org/10.17730/humo.32.1.3826q004412x5605.

Mansell-Carstens, Catherine. 1996. "Popular Financial Culture in Mexico: The Case of the Tanda," Changing Structure of Mexico: Political, Social, and Economic Prospects. Randall, Laura, ed. ME Sharpe, pp. 77-81.

Office of the Inspector General, U.S. Postal Service. 2014. "Providing Non-Bank Financial Services for the Underserved," White Paper, Arlington, VA: USPS OIG.

Quiñonez, José. 2015. "Hierarchy of Financial Needs: An Introduction.” Mission Asset Fund, https://missionassetfund.org/hierarchy-financial-needs-introduction/ (accessed November 6, 2019).

Reyes, Belinda, Elias Lopez, Sarah Phillips, and Kurt Schroeder. 2013a. "Building Credit for the Underbanked: Social Lending as a Tool for Credit Improvement," César E. Chávez Institute, San Francisco.

Reyes, Belinda, Elias Lopez, Sarah Phillips, and Kurt Schroeder. 2013b. "Replicating Lending Circles: Lessons Learned from Five Bay Area Communities," César E. Chávez Institute, San Francisco.

Reyes, Belinda, and Elias Lopez. 2016. "Social Lending: Improving Credit for the Underbanked," Communities and Banking, Winter 2016, Federal Reserve Bank of Boston.

Wherry, Frederick F., Kristin S. Seefeldt, Anthony S. Alvarez, and José Quiñonez. 2019. Credit Where It's Due: Rethinking Financial Citizenship, Russell Sage Foundation.

Wu, Xiaoyu, and Teresa D. Hutchins. 2015. "Immigrants Financing Immigrants: A Case Study of a Chinese-American Rotating Savings and Credit Association in Queens," New York Economic Review, 46, pp. 21-34. 


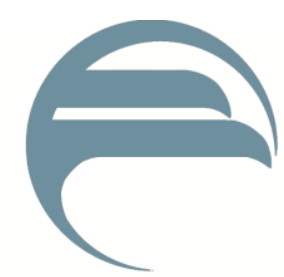

FEDERAL Reserve BANK of PHILADELPHiA

Consumer Finance Institute Discussion Paper Series

http://www.philadelphiafed.org/consumer-finance-institute 